\title{
Ecological standardization of permissible radionuclide pollutions of fresh water ecosystems on the basis of theory and models of radiocapacity
}

\author{
Yu. Kutlakhmedov and V. Kutlakhmedova-Vishnyakova \\ Taras Schevchenko National Kiev State University, Department of Radiobiology \\ and Radioecology, $01004 \mathrm{Kiev}$, Ukraine
}

\begin{abstract}
In the case of radionuclide releases and disposal into the environment it is important to assess the maximum admissible values of income of radionuclides into an ecosystem, where there are no yet noticeable biological changes as the result of ionising radiation. The natural boundary for estimation of maximum permissible disposal of radionuclides into ecosystems is the dose commitment or the annual absorbed dose rate. G. Polikarpov and V. Tsytsugina have proposed a scale of dose commitments to ecosystems consisting of four basic dose limits. From the given scale it follows that the real dose limit for release and accidental "disposal" of radionuclides in ecosystems and their components is the dose rate that exceeds $0.4 \mathrm{~Gy}^{-1}$ for terrestrial animals and $4 \mathrm{~Gy} \mathrm{y}^{-1}$ for hydrobionts and terrestrial plants. At such dose rates it is possible to expect a development of evident ecological effects in ecosystems. Dose commitments from $\alpha$, $\beta^{-}$, $\gamma$-radiation are not difficult to assess for the radionuclides composition of the Kyshtum and the Chernobyl releases. According to our assessments the calculated total dose of $0.4 \mathrm{~Gy} \mathrm{y}^{-1}$ to $4 \mathrm{~Gy}^{-1}$ (as given by Amiro, [4]) correspond to respective concentration of ${ }^{137} \mathrm{Cs}$ of about 100 and $1000 \mathrm{kBq} \mathrm{l}^{-1}\left(\mathrm{~kg}^{-1}\right)$ in ecosystem or in its elements (terrestrial plants and hydrobionts). The total dose $4 \mathrm{~Gy} \mathrm{y}^{-1}$ corresponds to ${ }^{137} \mathrm{Cs}$ concentration of about $1000 \mathrm{kBq} \mathrm{I}^{-1}\left(\mathrm{~kg}^{-1}\right)$ for a fresh water ecosystem. The maximum permissible releases of radionuclides into the ecosystems could be assessed on the basis of the above mentioned models and equations, using an assessment of maximum permissible concentration of radionuclides in the components of the ecosystem.
\end{abstract}

\section{INTRODUCTION}

A. Agre and V. Korogodin [1] were the first scientists who introduced the notion of the " radiocapacity factor" for a non-running freshwater pond in the zone of the "Mayak" Enterprises and the Kyshtum accident. The radiocapacity factor permits the calculation of the radionuclides portion accumulated in the pond bottom sediments that constitutes the critical link in the ecosystem and a source-term for the main amount of radionuclides released into the water body. The equation for calculating the radiocapacity factor is as follows : $F=\frac{k h}{H+k h}$

where, $\mathrm{k}$ : transfer factor of radionuclide in the bottom sediments versus water; $\mathrm{h}:$ thickness of the actively sorbed layer of bottom sediments; $\mathrm{H}$ : average depth of reservoir.

For freshwater lakes in the region of the Kyshtum and the Chernobyl accidents the calculated and measured values of $\mathrm{F}$ for ${ }^{137} \mathrm{Cs}$ amount from 0.6 to 0.9 , respectively. Equations for the calculation of the radiocapacity factor for the most different situations (closed water-bodies ecosystems, cascade of running-water ponds and reservoirs, slope ecosystems, water meadows, agro ecosystems) have been described elsewhere [2].

The mathematical method and theory of radiocapacity permit the description, comparison and assessment of different types of ecosystems from alone integral theoretical positions . 


\section{PROBLEMS OF ECOSYSTEM ECOLOGICAL STANDARDIZATION}

In the case of radionuclide releases and disposal into the environment, it is important to assess the maximum admissible values of radionuclides income into an ecosystem, prior to any noticeable biological change resulting from ionising radiation.

The natural boundary for estimation of the maximum permissible disposal of radionuclides into ecosystems is the dose commitment or the annual absorbed dose rate. G. Polikarpov and V. Tsytsugina have proposed a scale of dose commitments in ecosystems consisting of four basic zones with associated dose limits [3] which are presented in Table 1.

Table 1. The scale of dose commitments in ecosystems (from [3])

\begin{tabular}{|lc||}
\hline \multicolumn{1}{|c|}{ ZONE } & ABSORBED DOSE RATE (Gy $\mathbf{~}^{-1}$ ) \\
Zone of radiation well-being & $0.001-0.005$ \\
Zone of physiological masking & $0.005-0.05$ \\
Zone of ecological masking: & \\
$\quad$ for terrestrial animals & $0.05-0.4$ \\
for hydrobionts and terrestrial land plants & $0.05-4$ \\
Zone of evident ecological changes: & \\
$\begin{array}{l}\text { Dramatic: } \\
\text { for terrestrial animals } \\
\text { for hydrobionts and terrestrial plants }\end{array}$ & $>0.4$ \\
$\begin{array}{l}\text { Catastrophic: } \\
\text { animals and plants }\end{array}$ & $>4$ \\
\hline
\end{tabular}

From the given scale it follows that the real dose limit for routine release and accidental "disposal" of radionuclides in ecosystems and their components is the dose rate that exceeds $0.4 \mathrm{~Gy}^{-1}$ for terrestial animals and $4 \mathrm{~Gy} \mathrm{y}^{-1}$ for hydrobionts and terrestrial plants. At such dose rates the appearance of evident ecological effects in ecosystems is possibly expected. Dose commitments from $\alpha, \beta, \gamma$ radiation are not difficult to assess for the radionuclides composition of the Kyshtum and the Chernobyl releases. According to our assessments the calculated total doses of $0.4 \mathrm{~Gy} \mathrm{y}^{-1}$ and $4 \mathrm{~Gy} \mathrm{y}^{-1}$ (as given by Amiro [4]) correspond to respective concentration in the ecosystem of ${ }^{137} \mathrm{Cs}$ and about 100 and $\left.1000 \mathrm{kBq}\right|^{-1}\left(\mathrm{~kg}^{-1}\right)$ or its elements (terrestrial plants and hydrobionts). The total dose $0.4 \mathrm{~Gy}^{-1}$ corresponds to ${ }^{137} \mathrm{Cs}$ concentration of about $100 \mathrm{kBq} \mathrm{l^{-1 }}\left(\mathrm{kg}^{-1}\right)$ for an ecosystem with terrestrial animals.

The following consequences of effects in a freshwater ecosystem can take place:

1) Disappearance of reservoir population because of harmful dose effects;

2) Acidification of water;

3) Amplification of radionuclides desorption from bottom sediments;

4) Increase of radionuclides contamination in water;

5) Resulting additional dose for living components of ecosystems, etc.

Thus, if we intend to save an ecosystem well-being, we should not exceed these limits in ecosystems either as a whole or in their particular biotic components. It is necessary to underline that an existing system of standardization of radionuclides releases by NPP does not take into account these major limitations practically. However, the influence of these factors must be taken into account for creating a real system of ecological standardization.

\section{ASSESSMENT OF PERMISSIBLE DUMPING AND SELF-DISPOSAL OF RADIONUCLIDES IN A FRESHWATER RESERVOIR}

For a freshwater reservoir, the equation for evaluating of the radiocapacity factor of the biocenosis in the water column is as follows: 


$$
F_{b}=\frac{p H K_{b}}{p H K_{b}+k h+H}
$$

where, $p$ is the hydrobionta biomass in water (typically ranging from 1 to $10 \mathrm{gm}^{-3} ; \mathrm{K}_{\mathrm{b}}$ is the transfer factor in the biocenosis and its components (typically between 1000 and 100000).

$\mathrm{F}_{b}$ can range from 0.05 up to 0.97 , when practically all radionuclides are concentrated in the biotic components of the water body.

The maximum permissible releases of radionuclides into the ecosystems could be assessed on the basis of the above mentioned models and equations, using an assessment of maximum permissible concentration of radionuclides in the components of the ecosystem.

1. For benthos of bottom sediments in a freshwater water body, the maximum permissible release of radionuclides in the water body $\left(\mathrm{N}_{\mathrm{k}}\right)$ should not exceed:

$$
N_{k}<\frac{L h S}{k F}
$$

where $\mathrm{L}$ is the limit of concentration of radionuclides in the aquatic population $\left(640 \mathrm{kBq} \mathrm{kg}^{-1}\right)$ and $\mathrm{S}$ is the area of the water body .

2. For the water column population (pleuston, neuston, plankton, nekton) maximum permissible releases of radionuclides $\left(\mathrm{N}_{\mathrm{b}}\right)$ should not exceed:

$$
N_{b}<\frac{L H S}{K_{b}(1-F)}
$$

For a specific freshwater water body, where $S=2 \mathrm{~km}^{2}, \mathrm{H}=4 \mathrm{~m}, \mathrm{~K}_{\mathrm{b}}=1000, \mathrm{~F}=0.7$, the maximum permissible release of radionuclides is $\mathrm{N}_{b}<17.1 \mathrm{TBq}$ in the water of the whole water body. At the same time the maximum permissible release of radionuclides into a water body for its benthos was estimated using equation (4) $\mathrm{N}_{k}<0.18 \mathrm{TBq}$. This magnitude is 70 times less than the permissible release of radionuclides, which was assessed for the population of the water column .

In general cases, the maximum permissible releases of radionuclides into a water body are assessed by using the ratio between the two critical links (population of water column and benthos):

$$
\frac{N_{k}}{N_{b}}=\frac{h K_{b}(1-F)}{H k F}
$$

3. Similar evaluations of maximum permissible releases of radionuclides can be carried out also for other types of ecosystems. Particularly, in a system of cascades of reservoirs (such as the Dnieper cascade), the first reservoir (the Kiev reservoir) is critical for dose commitment. In bottom sediments of the upper part of the Kiev reservoir, the radionuclide content in bottom sediments reaches about $370 \mathrm{kBq} \mathrm{kg}^{-1}$ and more. In fact, this means that at the upper part of the reservoir the level of past release of radionuclides has reached the maximum permissible value. In the benthos population therefore, it is pnssible to expect noticeable ecological consequences. The theoretical maximum permissible release of radionuclides calculated in the Kiev reservoir is estimated at a total of $83 \mathrm{TBq}$, while the real content of ${ }^{13} \mathrm{Cs}$ in bottom sediments is estimated from local measurements at $200 \mathrm{TBq}$. This significantly exceeds the maximum permissible concentration [7].

4. In sea ecosystems, the bioproductivity develops mainly in shallow coastal water. With an

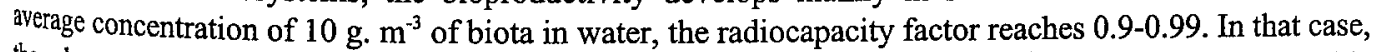
the release of large amounts of water with radionuclide content of $1.2-12 \mathrm{kBq}^{-1}$ can result in radionuclide contamination of the community up to $115 \mathrm{kBq} \mathrm{kg}^{-1}$. This is higher than an ecological permissible level. 


\section{ASSESSMENT OF MAXIMUM PERMISSIBLE RELEASES AND DISPOSAL OF RADIONUCLIDES IN SLOPE ECOSYSTEMS CONNECTED WITH LAKE.}

The prime model developed for evaluating the radiocapacity of a slope ecosystem, is based on assessment of the dynamics, time and place of excepted concentration of radionuclides in some elements of the slope ecosystem. The radiocapacity factor can be determined by the equation (7).

$$
F_{s}=1-\prod_{i=1}^{k} P_{i=1}-P_{s}
$$

where, $P_{i}$ is the probability of radionuclides flow from an appropriate element of the slope ecosystem ina year, $\mathrm{P}_{1}=$ flow from forest ecosystem, $\mathrm{P}_{2}=$ flow from stony plot, $\mathrm{P}_{3}=$ flow from meadow ecosystem, $\mathrm{P}_{4}$ = flow from terrace in a lake and $P_{s}=$ multiplay $P i$. Practically, it means, that parameters of migration and concentration of radionuclides in a forest (top of slope ecosystem), on the border of a forest, on water-meadow, and/or in bottom sediments along the water flow (river, brook, lake, bog etc.) determine the maximum permissible releases of radionuclides into a given ecosystem, as follows:

$$
N_{k}(f)<\frac{N_{k}(L)}{P_{s} \times T}
$$

where, $N_{k}(L)$ is .determined from equation (3), $T$ the duration of flow in years (evaluation for 20 years were used). As an example, a simple slope ecosystem has been selected : Forest $\Rightarrow$ Stony plot $\Rightarrow$ Meadow $\Rightarrow$ Terrace $\Rightarrow$ Lake. The initial contamination of the forest was $3.7 \mathrm{~TB}$. (Radioactive decay was not taken into consideration for simplicity). In the given slope ecosystem, the limiting link according to dynamics of radionuclides redistribution is the bottom sediments of the final element of the ecosystem (lake). Practically, $80 \%$ of the initial content of radionuclides is concentrated in the lake bottom sediments. At $\mathrm{S}=2 \mathrm{~km}^{2}, \mathrm{~N}_{\mathrm{k}}$ for a such lake was assessed from equation (3) to amout $47 \mathrm{GBq}$. In order to fulfil the ecological standards for benthos of the lake bottom sediments, it is necessary that the total content of radionuclides on water catchment area of the lake should not exceed $57-70 \mathrm{GBq}$. When taking $10 \mathrm{~km}^{2}$ as the water catchment area, the density of contamination has not to exceed $100 \mathrm{kBq} \mathrm{m}^{-2}$. It must be noticed that the existing levels of radionuclide contamination in the $30-\mathrm{km}$ ChNPP zone and other territories of Ukraine, Byelorussia and Russia exceeded $100 \mathrm{kBq} \mathrm{m}^{-2}$.

It is noticeable, that the permissible levels of radionuclides contamination are decreasing as one approaches the lake. Strictly speaking, the ecological norm depends on the ecosystem character. The closer to the critical unit (lake) and the higher the probability of drain, the lower the ecological specification of permissible contamination will be.

Practically it means, that initial radionuclides contamination of a territory (forest, for example) may be rather satisfactory for an initial situation. However, in a result of surface run-off and/or migration of radionuclides one may " receive" a significant concentration of radionuclides in any critical element of the ecosystem, therefore producing an excess to the maximum permissible concentration $\left(100 \mathrm{~Bq}^{-1}\right)$. Thus, initial "well-being" in radionuclide contamination of an ecosystem, may mean "future" harm depending on rates of transfer processes and concentration of radionuclides.

From extensive research in this zone, it has already been observed an excess of radionuclide contamination level $\left(100 \mathrm{kBq} \mathrm{kg}^{-1}\right)$ in bottom sediments of small lakes. As a consequence, changes in the characteristics of species population and communities, which inhabit bottom sediments of these lakes may be registered. We highlight, that this area of observation, given the actual and expected further effects in benthic organisms, deserves the most accurate attention. It is very important for establishing the System of Ecological Standardization [8].

\section{CONCLUSIONS}

1. A scale of dose commitment in ecosystems allows evaluating the maximum permissible concentrations of radionuclides. Above these concentrations it is possible to expect a noticeable influence on the ecosystem structure, on its biological characteristics and on the parameters of radiocapacity. 
2. Radionuclide redistributions in different types of ecosystems, which are approached by radiocapacity models, have allowed defining maximum permissible releases of radionuclides in particular "compartments" of ecosystems on the basis of ecological standardization.

3. In selected ecosystems (pond, water-cooling pond, forest etc.) general ecological maximum permissible releases of radionuclides are determined: a) by initial radionuclides contamination of an ecosystem and its elements; b) by dynamics of redistribution of radionuclides; c) by radiocapacity parameters of the ecosystems.

4. The proposed method of assessment of ecological maximum permissible radionuclide contamination of ecosystems and their components may be used as a theoretical basis for the System of Ecological Standardization of radionuclides releases from NPPs in normal and accidental conditions.

References

[1] Agre A.L. and Korogodin V.I.: About Distribution of Radioactive Pollutions in Nonflowing Reservoir, Med.Radiology N1: (1960) 67-73 (in Russian).

[2] Kutlakhmedov Y., Polikarpov G, and Kutlakhmedova-Vyshnyakova: Radiocapacity of Different types of Natural Ecosystems and Ecological Standartization Principles. J. Radioecology.- V.6(2) (1997), p/15-21

[3] Polikarpov G.G. and Tsytsugina V.C. : After Effects of Kyshtum and Chernobyl Accidents on Hydrobionts (1995), Radiation Biology. Radioecology., Vol.35 N4: 536-548 (in Russian).

[4] Amiro B.D.: Radiological Dose Conversion Factors for Generic Non-human Biota. Used for Screening Potential Ecologycal Impacts, J. Environ. Radioactivity Vol.35, N1 (1992) : 37-51.

[5] Antropogenic Radionuclides Anomaly and Plants. Kiev, Lebid, (1991) 160 p. (In Russian).

[6] Kutlakhmedov Y.A., Polikarpov G.G. and Korogodin V.I. : Principles and Methods of Ecosystems Radiocapacity Estimation. In: D.Grodsinsky (Ed.) Heuristic of radiobiology. Kiev, Naukova dumk (1988): pp. 60-66. (in Russian).

[7] Radioactive and Chemical Pollution of Dnieper and it Reservoirs after Chernobyl Accident : Kiev, Naukova Dumka, (1992) 195 p.

[8] Kutlakhmedov Y.A. and Korogodin V.I. Bases of Radioecology, Kiev, High school, (2001) 420 p, (in press). 